\title{
The Rabbit Pulmonary Cytochrome P450 Arachidonic Acid Metabolic Pathway: Characterization and Significance
}

\author{
Darryl C. Zeldin, ${ }^{*}$ Jonathan D. Plitman, ${ }^{\star}$ Jun Kobayashi, ${ }^{*}$ Robert F. Miller, ${ }^{\star}$ James R. Snapper, ${ }^{*}$ John R. Falck, ${ }^{\$}$ \\ John L. Szarek," Richard M. Philpot, ' and Jorge H. Capdevila** \\ Departments of ${ }^{*}$ Medicine and ${ }^{\ddagger}$ Biochemistry, Vanderbilt University Medical School, Nashville, Tennessee $37232 ;{ }^{8}$ Department \\ of Molecular Genetics, University of Texas Southwestern Medical Center, Dallas, Texas 75235; "Department of Pharmacology, \\ Marshall University School of Medicine, Huntington, West Virginia 25755; and 'Laboratory of Cellular and Molecular Pharmacology, \\ National Institute of Environmental Health Sciences, Research Triangle Park, North Carolina 27709
}

\section{Abstract}

Cytochrome P450 metabolizes arachidonic acid to several unique and biologically active compounds in rabbit liver and kidney. Microsomal fractions prepared from rabbit lung homogenates metabolized arachidonic acid through cytochrome P450 pathways, yielding cis-epoxyeicosatrienoic acids (EETs) and their hydration products, vic-dihydroxyeicosatrienoic acids, mid-chain cis-trans conjugated dienols, and 19- and 20-hydroxyeicosatetraenoic acids. Inhibition studies using polyclonal antibodies prepared against purified CYP2B4 demonstrated $100 \%$ inhibition of arachidonic acid epoxide formation. Purified CYP2B4, reconstituted in the presence of NADPH-cytochrome P450 reductase and cytochrome $b_{5}$, metabolized arachidonic acid, producing primarily EETs. EETs were detected in lung homogenate using gas chromatography/mass spectroscopy, providing evidence for the in vivo pulmonary cytochrome $\mathbf{P 4 5 0}$ epoxidation of arachidonic acid. Chiral analysis of these lung EETs demonstrated a preference for the $14(R), 15(S)$-, $11(S), 12(R)$-, and $8(S), 9(R)$-EET enantiomers. Both EETs and vic-dihydroxyeicosatrienoic acids were detected in bronchoalveolar lavage fluid. At micromolar concentrations, methylated 5,6-EET and 8,9-EET significantly relaxed histamine-contracted guinea pig hilar bronchi in vitro. In contrast, 20-hydroxyeicosatetraenoic acid caused contraction to near maximal tension. We conclude that CYP2B4, an abundant rabbit lung cytochrome $\mathbf{P 4 5 0}$ enzyme, is the primary constitutive pulmonary arachidonic acid epoxygenase and that these locally produced, biologically active eicosanoids may be involved in maintaining homeostasis within the lung. (J. Clin. Invest. 1995. 95:2150-2160.) Key words: eicosanoid • epoxygenase - epoxyeicosatrienoic

Portions of this work were presented at the 1992 International Conference of the American Thoracic Society, May 17-20, Miami Beach, FL, and the 1993 International Conference of the American Thoracic Society, May 16-19, San Francisco, CA.

Address correspondence to Darryl C. Zeldin, Laboratory of Pulmonary Pathobiology, National Institutes of Health, National Institute of Environmental Health Sciences, P.O. Box 12233, Research Triangle Park, NC 27709. Phone: 919-541-1169; FAX: 919-541-4133.

Received for publication 31 August 1994 and in revised form 18 November 1994.

J. Clin. Invest.

(c) The American Society for Clinical Investigation, Inc. 0021-9738/95/05/2150/11 \$2.00

Volume 95, May 1995, 2150-2160 acid - dihydroxyeicosatrienoic acid - hydroxyeicosatetraenoic acid

\section{Introduction}

Arachidonic acid is present in vivo esterified to the $s n-2$ position of cellular glycerophospholipids (1). Activation of hormonally sensitive phospholipases releases arachidonic acid (AA) ${ }^{1}$ from the phospholipid pools, thus making it available for oxygenation by three different enzyme systems (1-3). $\mathrm{PGH}_{2}$ synthases metabolize arachidonic acid, yielding $\mathrm{PGH}_{2}$, which serves as the precursor of the prostaglandins, thromboxane, and prostacycline $(2,3)$. Lipoxygenases convert arachidonic acid to unstable hydroperoxy intermediates that go on to form the leukotrienes and hydroxyeicosatetraenoic acids (HETEs) $(2,3)$. Cytochrome $\mathrm{P} 450$ arachidonic acid monooxygenases catalyze the formation of epoxides (EETs), mid-chain cis-trans conjugated dienols (HETEs), and C-19/C-20 alcohols (19-OH-AA and 20-OHAA) $(2,3)$.

The role of cytochrome P450 in the NADPH-dependent oxygenation of arachidonic acid in extrapulmonary tissues is well established (4-6). The P450-derived arachidonic acid metabolites have numerous biological activities, including effects on vascular tissues $(7-10)$, modulation of membrane ion fluxes (11-13), stimulation of peptide hormone release $(14,15)$, inhibition of cyclooxygenase activity and platelet aggregation (16), angiogenic effects (17), and effects on neutrophil chemotaxis (18). McGiff (11) has recently proposed that the renal arachidonic acid monooxygenase is involved in the pathophysiology of hypertension. Using chiral-phase HPLC techniques, our laboratory has demonstrated that EET production by rat liver and kidney microsomal fractions is stereoselective and under P450 enzyme control $(19,20)$. Furthermore, chiral analysis of endogenous EET pools in rat liver (21), kidney (7), and plasma (22) demonstrates that the $14(R), 15(S)-, 11(S), 12(R)-$, and $8(S), 9(R)$-EET enantiomers predominate. The EETs are enzymatically hydrated by epoxide hydrolases to produce the corresponding vic-dihydroxyeicosatrienoic acids (DHETs) $(23,24)$. The cytosolic epoxide hydrolase shows high affinity for the EETs $\left(K_{\mathrm{m}}<5 \mu \mathrm{M}\right)$ and a selectivity for the endogenous enanti-

1. Abbreviations used in this paper: AA, arachidonic acid; BAL, bronchoalveolar lavage; DHET, vic-dihydroxyeicosatrienoci acid; EET, cisepoxyeicosatrienoic acid; GC, gas chromatography; HETE, hydroxyeicosatetraenoic acid; Me, methyl; MS, mass spectroscopy; NICI, negative-ion chemical ionization; P450, cytochrome P450 monooxygenase; PFB, pentafluorobenzyl; PSS, physiologic salt solution; $R_{t}$, retention time; TMS, trimethylsilyl. 
omers (23). Importantly, the urinary excretion of DHETs is increased in pregnancy-induced hypertension (25).

Much of what we know about the cytochrome P450 monooxygenase system is derived from studies in hepatic tissues. Less is known about the pulmonary P450 monooxygenase system. Rabbit lung contains significant quantities of cytochromes P450 $(26,27)$, NADPH-cytochrome P450 reductase $(27,28)$, and epoxide hydrolases (29). These components have been shown by in situ hybridization and immunolocalization to be present primarily within Clara cells and type II pneumocytes, although they have also been detected in alveolar macrophages, goblet cells, and endothelial cells (26-28). Despite studies on the components of the pulmonary P450 system and their localization, the physiological significance of this enzyme system is unknown (30-32). Pulmonary P450 has long been thought to function primarily in the metabolism of exogenous compounds (including drugs and inhaled carcinogens) (30). Only recently has the pulmonary P450 metabolism of endogenous substances been reported $(33,34)$. We demonstrate here an active role for this enzyme system in the regio- and stereoselective oxygenation of arachidonic acid and suggest that its products may be of significance to lung physiology.

\section{Methods}

Preparation of microsomal fractions. Male New Zealand White rabbits (3-4 kg) were killed by lethal intravenous injection of sodium pentobarbital $(50-60 \mathrm{mg} / \mathrm{kg}$ ) and then exsanguinated by perforation of the right ventricle. The lungs were perfused in situ via the main pulmonary artery with ice-cold $0.15 \mathrm{M} \mathrm{KCl}$ and then removed, weighed, minced, washed twice with the perfusing solution, and immediately homogenized in 0.01 $\mathrm{M}$ Tris-Cl buffer, $\mathrm{pH} 7.5$, containing $0.25 \mathrm{M}$ sucrose $(20 \mathrm{~g}$ of wet tissue per $100 \mathrm{ml}$ ). Microsomal fractions were obtained by differential centrifugation at $4^{\circ} \mathrm{C}$ as previously described (35) and used within 48 $h$ of preparation. Protein determinations were performed according to the method of Bradford (36).

Microsomal incubations. Reaction mixtures containing $0.05 \mathrm{M}$ Tris$\mathrm{Cl}$ buffer, $\mathrm{pH} 7.5,0.15 \mathrm{M} \mathrm{KCl}, 0.01 \mathrm{M} \mathrm{MgCl}_{2}, 8 \mathrm{mM}$ sodium isocitrate, $0.5 \mathrm{IU} / \mathrm{ml}$ isocitrate dehydrogenase, and $1.0 \mathrm{mg} / \mathrm{ml}$ microsomal protein were constantly stirred at $30^{\circ} \mathrm{C}$. After temperature equilibration, [1${ }^{14} \mathrm{C}$ ] arachidonic acid $(0.8-1.2 \mu \mathrm{Ci} / \mu \mathrm{mol})$ was added to a final concentration of 75-100 $\mu \mathrm{M}$. $1 \mathrm{~min}$ later, NADPH ( $1 \mathrm{mM}$, final concentration) was added. At 15-min intervals, aliquots were withdrawn, and the reaction products were extracted into ethyl ether, dried under a nitrogen stream, and analyzed by HPLC (35).

Incubations in reconstituted systems using purified pulmonary P450 enzymes. CYP2B4 and CYP4B1 were purified from rabbit lung microsomal fractions according to published procedures (37). The enzymes were judged homogeneous based on their electrophoretic properties (37). NADPH-cytochrome P450 reductase and cytochrome $b_{5}$ were purified as described $(38,39)$. The metabolism of arachidonic acid by purified P450s was reconstituted as previously described (19). Briefly, purified P450, NADPH-cytochrome P450 reductase, and cytochrome $b_{5}$ ( $1 \mu \mathrm{M}$ each, final concentration) were mixed in the presence of sonicated L- $\alpha$-dilauroyl-sn-glycero-3-phosphocholine $(100-200 \mu \mathrm{g} / \mathrm{ml})$. After $15 \mathrm{~min}$ at $4^{\circ} \mathrm{C}$, the mixture was diluted fivefold with $0.05 \mathrm{M}$ Tris$\mathrm{Cl}$ buffer, $\mathrm{pH} 7.5$, containing $0.15 \mathrm{M} \mathrm{KCl}, 0.01 \mathrm{M} \mathrm{MgCl}_{2}, 8 \mathrm{mM}$ sodium isocitrate, and $0.5 \mathrm{IU} / \mathrm{ml}$ isocitrate dehydrogenase. Addition of $\left[1-{ }^{14} \mathrm{C}\right]-$ arachidonic acid (75-100 $\mu \mathrm{M}$, final concentration) was followed by initiation with NADPH ( $1 \mathrm{mM}$, final concentration). Incubations were done with constant mixing at $30^{\circ} \mathrm{C}$. At different time points, samples were withdrawn, extracted into ethyl ether, dried under a nitrogen stream, and analyzed by HPLC (35).

Antibody inhibition studies. Polyclonal antibodies against purified rabbit lung P450 enzymes CYP2B4 and CYP4B1 and against NADPH- cytochrome P450 reductase were prepared as described (40). The immunospecificity of the anti-CYP2B4, anti-CYP4B1, and anti-reductase antibodies have been validated by Ouchterlony double immunodiffusion (40) and protein immunoblotting of lung microsomal fractions (41). Purified immune IgG or the corresponding control, nonimmune IgG fractions were added to the microsomal incubates at immunoglobulin/ hemeprotein ratios ranging from 0.5 to $5 \mathrm{mg}$ of $\mathrm{IgG}$ per $\mathrm{mg}$ of microsomal protein. After $20 \mathrm{~min}$ at $22^{\circ} \mathrm{C},\left[1-{ }^{14} \mathrm{C}\right]$ arachidonic acid was added (75-100 $\mu \mathrm{M}$, final concentration), the temperature was raised to $30^{\circ} \mathrm{C}$, and the reaction was initiated by adding NADPH. Metabolites were extracted and resolved by HPLC (35).

Quantification of endogenous EETs in lung homogenate. Lungs were removed, perfused as previously described, and immediately homogenized in methanol/water $(2: 3,20 \mathrm{ml}$ per $\mathrm{g}$ of wet tissue) containing triphenylphosphine $(0.1 \mathrm{mM}$, final concentration). An aliquot of the homogenate, corresponding to $0.5 \mathrm{~g}$ of lung wet tissue, was transferred to a test tube containing an equivalent volume of a $2-\mathrm{mM}$ solution of triphenylphosphine in chloroform and a mixture of $\left[1-{ }^{14} \mathrm{C}\right] 8,9-11,12-$, and 14,15-EET (52-55 $\mu \mathrm{Ci} / \mu \mathrm{mol}, 30 \mathrm{ng}$ each) as internal standards. After mixing, $\mathrm{HCl}$ was added to a final concentration of $0.75 \mathrm{M}$, and the suspension was centrifuged to effect phase separation. The aqueous phase was extracted once more with $2 \mathrm{vol}$ of chloroform/methanol (2:1), the organic mixture was neutralized by the addition of $6 \mathrm{M} \mathrm{NaOH}$, and the combined organic phases were evaporated under a nitrogen stream. Phospholipid-bound EETs were recovered by saponification (21), and the resulting material was dissolved in acetic acid/hexane (0.5:99.5 [vol/vol]) and applied to a $\mathrm{SiO}_{2}$ column (200-400 mesh, $5 \times 20$ $\mathrm{mm})(21)$. The EETs were eluted with acetic acid/ethyl ether/hexane $(0.5: 50: 49.5[\mathrm{vol} / \mathrm{vol} / \mathrm{vol}])$, and the eluent, containing a mixture of radiolabeled internal standards and total endogenous EETs, was resolved into individual regio- and stereoisomers by HPLC as described (21, 42, 43).

Quantification of endogenous EETs and DHETs in bronchoalveolar lavage fluid. Rabbits were anesthetized with sodium pentobarbital (40$50 \mathrm{mg} / \mathrm{kg}$ ), and the thoracic cavity was entered to effect lung collapse and to allow direct visualization during lavage. The trachea was dissected free and cannulated. Bronchoalveolar lavage (BAL) was performed by instillation and withdrawal of three $60-\mathrm{ml}$ aliquots of normal saline. The BAL fluid was immediately placed on ice in a flask containing triphenylphosphine (1 $\mathrm{mg}$ per $\mathrm{ml}$ of BAL fluid). BAL samples were extracted twice with $2 \mathrm{vol}$ of chloroform/methanol (2:1) and once more with an equal volume of chloroform. The combined organic phases were concentrated and evaporated in tubes containing mixtures of [1$\left.{ }^{14} \mathrm{C}\right] 8,9-, 11,12-$, and $14,15-E E T$ and $\left[1-{ }^{14} \mathrm{C}\right] 5,6-, 8,9-, 11,12-$, and 14,15 -DHET internal standards ( $52-55 \mu \mathrm{Ci} / \mu \mathrm{mol}, 30 \mathrm{ng}$ each ). Saponification to recover phospholipid-bound EETs (21) was followed by $\mathrm{SiO}_{2}$ column purification (21). The eluent, containing a mixture of radiolabeled internal standards and total endogenous EETs and DHETs, was resolved into individual regioisomers by $\operatorname{HPLC}(21,35)$. In some experiments, BAL fluid cells, obtained by centrifugation at $600 \mathrm{~g}$ for $15 \mathrm{~min}$, were analyzed separately. Phospholipid-bound EETs were quantified as described previously $(22,44)$.

Gas chromatography/mass spectroscopy analysis. For analysis of EETs, aliquots of the individual EET-pentafluorobenzyl esters (EETPFBs) were dissolved in dodecane and analyzed by gas chromatography/negative-ion chemical ionization/mass spectroscopy (GC/NICI/ MS) on a Nermag R1010C quadrupole instrument (Nermag Corp., Malmarson, France) as described (21). Quantifications were made by $\mathrm{GC} / \mathrm{NICI} /$ selected ion monitoring at $\mathrm{m} / \mathrm{z} 319$ (loss of PFB from endogenous EET-PFB) and $\mathrm{m} / \mathrm{z} 321$ (loss of PFB from $\left[1-{ }^{14} \mathrm{C}\right] \mathrm{EET}-\mathrm{PFB}$ internal standard) (Fig. 1). The EET-PFB $/\left[1-{ }^{14} \mathrm{C}\right]$ EET-PFB ratios were calculated from the integrated values of the corresponding ion current intensities. For analysis of DHETs, aliquots of the individual DHETPFB-trimethylsilyl ether (DHET-PFB-TMS) derivatives were dissolved in dodecane and analyzed by GC/NICI/MS as described (20). Quantifications were made by GC/NICI/selected ion monitoring at $\mathrm{m} / \mathrm{z} 481$ (loss of PFB from endogenous DHET-PFB-TMS) and $\mathrm{m} / \mathrm{z} 483$ (loss of PFB from $\left[1-{ }^{14} \mathrm{C}\right]$ DHET-PFB-TMS internal standard). The DHET- 


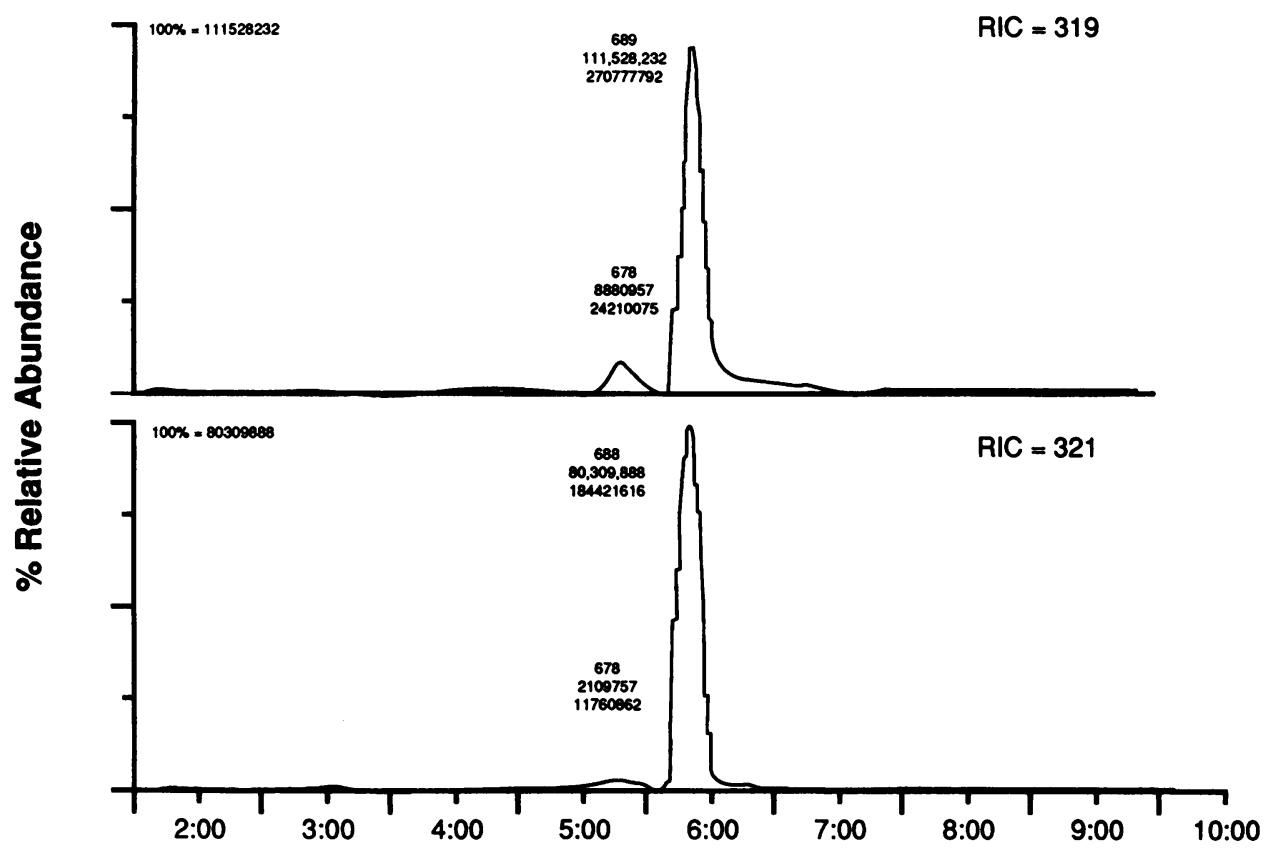

Retention Time (minutes)
Figure 1. Selected ion current profile under NICI conditions for 14,15-EET extracted from rabbit BAL fluid. Purified rabbit BAL fluid 14,15-EET-PFB was analyzed by GC/NICI/selected ion monitoring at $\mathrm{m} / \mathrm{z} 321$ and 319 as described in Methods. The samples' ${ }^{12} \mathrm{C} /{ }^{14} \mathrm{C}$ ratios were calculated from the integration of the area under the observed peaks.
PFB-TMS $/\left[1-{ }^{14} \mathrm{C}\right] \mathrm{DHET}-\mathrm{PFB}-\mathrm{TMS}$ ratios were calculated from the integrated values of the corresponding ion current intensities.

Synthetic procedures. Racemic EETs were prepared as previously described $(45,46)$. The enantiomers of 14,15 - and 8,9-EET were prepared by total asymmetric synthesis according to published procedures $(47,48) .\left[1-{ }^{14} \mathrm{C}\right]$ EETs were synthesized from $\left[1-{ }^{14} \mathrm{C}\right]$ arachidonic acid (52-57 $\mu \mathrm{Ci} / \mu \mathrm{mol}$ ) by nonselective epoxidation (49). Enantiomerically pure $\left[1-{ }^{14} \mathrm{C}\right] \mathrm{EET}$ s were obtained by chiral-phase HPLC separation of racemic $\left[1-{ }^{14} \mathrm{C}\right]$ EETs $(42)$. DHETs and $\left[1-{ }^{14} \mathrm{C}\right]$ DHETs were prepared by chemical hydration of individual EETs as described (23). All synthetic EETs and DHETs were purified by reverse-phase HPLC (35). 20-HETE was synthesized as described (50) and purified by reversephase HPLC (51). PGE 2 was obtained from Sigma Chemical Co. (St. Louis, MO) and was used without further purification. Methylations were performed using an ethereal solution of diazomethane (52). PFB esters were formed by reaction with PFB bromide as described (21). TMS ethers were prepared using $25 \%$ ( $\mathrm{vol} / \mathrm{vol}$ ) bis(trimethylsilyl)trifluoroacetamide in anhydrous pyridine as previously described (53).

Isolation of poly $(A)^{+} m R N A$ and Northern analysis. Rabbits were sacrificed as previously described, and their livers, lungs, kidneys, hearts, and brains were removed, immediately frozen in liquid nitrogen, and stored at $-80^{\circ} \mathrm{C}$. Within the next $48 \mathrm{~h}$, total RNA was extracted by homogenization of frozen tissue in $5.5 \mathrm{M}$ guanidinium thiocyanate containing $25 \mathrm{mM}$ sodium citrate, $0.5 \%$ (wt/vol) sodium $N$-lauryl sarcosine, and $0.2 \mathrm{M} 2$-mercaptoethanol, shearing of DNA by repeated passage through a 20-gauge needle, and density gradient centrifugation on a cushion of $5.7 \mathrm{M} \mathrm{CsCl}$ containing $0.1 \mathrm{M}$ EDTA (54). Poly (A) ${ }^{+}$ mRNA was prepared by the oligo(dT)-cellulose method using an mRNA purification kit (Pharmacia LKB Biotechnology Inc., Almeda, CA). After ethanol precipitation and quantification by spectrophotometry, the poly $(\mathrm{A})^{+}$mRNA $(2-5 \mu \mathrm{g})$ was denatured and electrophoresed in a $1.2 \%$ agarose gel containing $0.2 \mathrm{M}$ formaldehyde as described (54). After transfer to a nitrocellulose membrane, the blots were hybridized with the following sequence-specific oligonucleotide probes: CYP1A1 (5'-ACACCTGGACGTTGGCATTCTCGTCCAACC-3', complementary to residues 674-703 of the CYP1A1 cDNA clone) (55); CYP2B4 and CYP2B5 ( $5^{\prime}$-AGGAAAGCCAGGAGGAGGAGCAGGCTGAACTCCAT-3', complementary to residues $16-50$ of the CYP2B4 cDNA clone and residues 38-72 of the CYP2B5 cDNA clone) (56); CYP4B1 (5'-CCCACAGGCCCAGGCGGGAGAGGAAGCCGAGCATC-3', complementary to residues 24-58 of the CYP4B1 cDNA clone) (57); and a consensus oligonucleotide probe to CYP2C1, CYP2C2, CYP2C3, CYP2C4, CYP2C5, CYP2C14, CYP2C15, and CYP2C16 (5'-GGG(C)TCCTGTCCTGCATGCAGGGGC-3', complementary to residues 1063-1086 of the CYP2C16 cDNA clone) (58). Hybridizations were performed at $42^{\circ} \mathrm{C}$ in $50 \%$ formamide containing $0.75 \mathrm{M} \mathrm{NaCl}, 0.1 \%$ (wt/vol) SDS, $0.1 \%$ (wt/vol) sodium pyrophosphate, $4 \times$ Denhardt's solution, and $100 \mu \mathrm{g} / \mathrm{ml}$ salmon sperm DNA. Oligonucleotides were synthesized using the Cyclone Oligonucleotide Synthesizer (Waters Assoc., Marlborough, MA), purified by the Poly-Pak Cartridge Purification System (Glen Research Co., Sterling, VA), and end labeled using T4 polynucleotide kinase and $\left[\gamma^{32} \mathrm{P}\right]$ ATP $(59)$.

Measurement of airway smooth muscle contractile force. Male Hartley guinea pigs (480-590 g) were sacrificed with an intraperitoneal overdose of urethane. Their lungs were removed and placed in physiological salt solution (PSS; composition: $117 \mathrm{mM} \mathrm{NaCl}, 4.75 \mathrm{mM} \mathrm{KCl}$, $2.8 \mathrm{mM} \mathrm{CaCl}, 1.19 \mathrm{mM} \mathrm{KH} \mathrm{KO}_{4}, 1.19 \mathrm{mM} \mathrm{MgSO}{ }_{4}, 24.6 \mathrm{mM}$ $\mathrm{NaHCO}_{3}, 5 \mathrm{mM}$ glucose, $0.027 \mathrm{mM} \mathrm{CaNa}{ }_{2} \mathrm{EDTA}$ ) aerated with $95 \%$ air $/ 5 \% \mathrm{CO}_{2}$ at $22^{\circ} \mathrm{C}$. Using a dissecting microscope, cylindrical segments of hilar bronchi (1.5-2.0 mm in length) were isolated from both lungs and cleaned of adherent tissue. Similar to methods used to study isolated rat airways $(60)$, the segments were threaded onto two tungsten wires $50 \mu \mathrm{m}$ in diameter. One of the wires was fixed to a plastic holder that was attached to a microdisplacement device. The other wire was fixed to a holder that was mounted on an isometric transducer (Harvard Apparatus, South Natick, MA) to measure contractile force $(F)$. The airway segments were placed in 5-ml tissue baths containing PSS at $37^{\circ} \mathrm{C}$ and aerated with a mixture of air and $\mathrm{CO}_{2}$ such that the $\mathrm{P}_{\mathrm{CO} 2}$ and $\mathrm{P}_{\mathrm{O} 2}$ were maintained at 40 and $140 \mathrm{mmHg}$, respectively. The internal circumference $\left(C_{\mathrm{I}}\right)$ of each tissue was incrementally changed by increasing the distance between the wires using the microdisplacement device to achieve an equilibrated resting force $\left(F_{\mathrm{R}}\right)$ of $100 \mathrm{mg}$. This $C_{\mathrm{I}}$ was maintained throughout the experiment. Mechanical responses were recorded on a four-channel strip chart recorder (Linearecorder WR3101; Western Graphtec, Irvine, CA).

The airway segments were allowed to equilibrate for $30-60 \mathrm{~min}$ at 


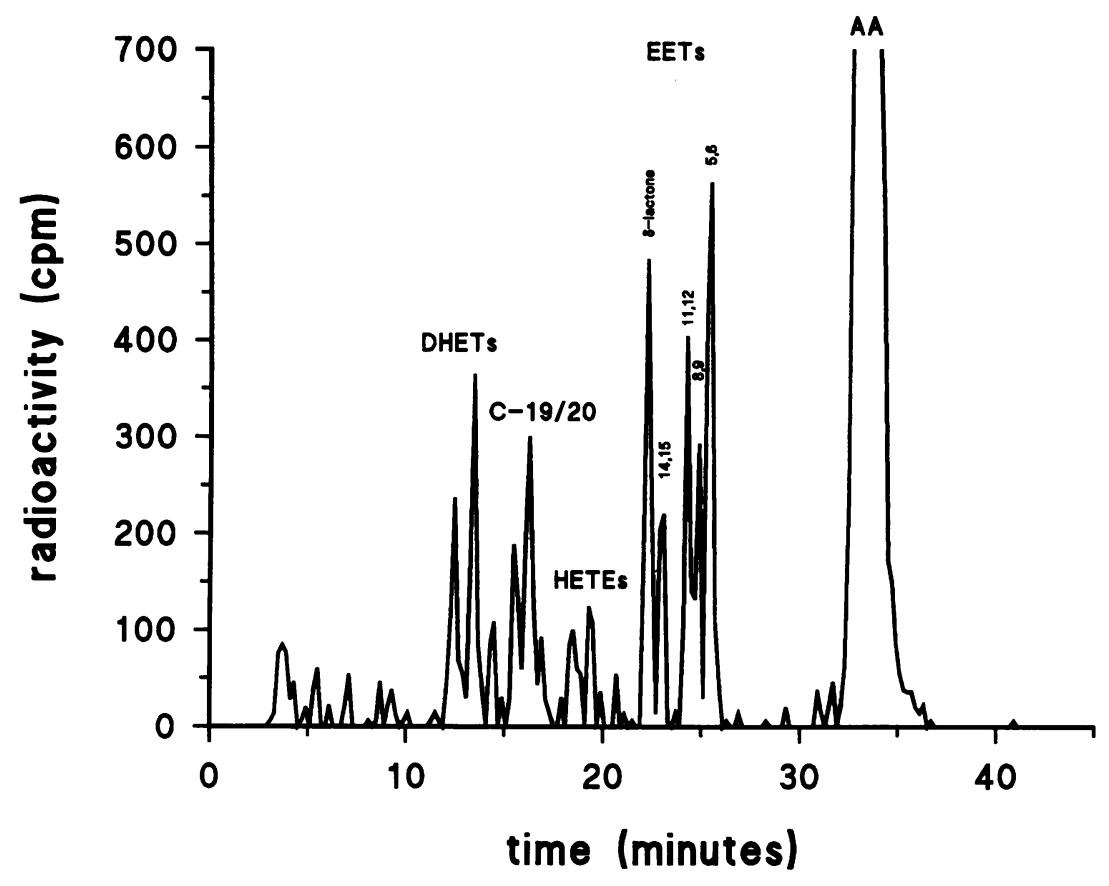

Figure 2. Reverse-phase HPLC chromatogram of organic soluble metabolites generated by incubations of rabbit lung microsomal fractions with arachidonic acid. Microsomal fractions $(1 \mathrm{mg} / \mathrm{ml}$ protein) were incubated with $\left[1-{ }^{14} \mathrm{C}\right]$ arachidonic acid $(100 \mu \mathrm{M})$ at $30^{\circ} \mathrm{C}$ for $30 \mathrm{~min}$ in the presence of NADPH ( $1 \mathrm{mM}$ ) and an NADPH-regenerating system. The ethyl ether-soluble products were resolved by reverse-phase HPLC, and the eluent radioactivity was monitored with an on-line radioactive flow detector. the appropriate $C_{\mathrm{I}}$, during which time they were washed with fresh PSS every $15 \mathrm{~min}$. Reference contractile force of each tissue to $1 \mathrm{mM}$ bethanechol $\left(F_{\mathrm{MAX}}\right)$ was then determined. Baths were then washed with fresh PSS, and the tissues were allowed to equilibrate again at $F_{\mathrm{R}}$ over 45-60 min with washes of fresh PSS every $15 \mathrm{~min}$. At this point, concentrations of histamine sufficient to produce a stable contractile force of $\sim 50 \%$ of $F_{\text {MAX }}\left(F_{\mathrm{HIST}}\right)$ were incrementally added to the baths. Methylated 5,6-EET (5,6-EET-Me), 8,9-, 11,12- and 14,15-EET, 20$\mathrm{OH}-\mathrm{AA}$, and $\mathrm{PGE}_{2}$ were dissolved in ethanol $(1 \mathrm{mM}$, final concentration) and serially diluted with PSS to allow concentration-response studies on the contractile force of the tissues at test compound concentrations ranging from $10^{-10}$ to $10^{-5} \mathrm{M}$. Control tissues were studied using the ethanol/PSS vehicle in equivalent volumes $(1 \mathrm{mM}$, final ethanol concentration in the baths). After each incremental change in test compound concentration, $F$ was monitored for at least $3 \mathrm{~min}$ or until a stable response was reached. At the end of the protocol, $1 \mu \mathrm{M}$ isoproterenol was added to the baths, and $F$ was monitored until a stable decrement in $F_{\text {HIST }}$ was achieved. The maximum responses of the tissues to each alteration of the bath composition were expressed as $\% \Delta F_{\text {HIST }}$ and analyzed by repeated measures analysis of variance with contrast analysis of the planned comparisons (Statistica/W; StatSoft, Tulsa, OK).

\section{Results}

In vitro metabolism of arachidonic acid by pulmonary P450. Incubations of rabbit lung microsomal fractions with $\left[1-{ }^{14} \mathrm{C}\right]-$ arachidonic acid in the presence of NADPH resulted in the formation of EETs, DHETs, HETEs, and C-19/C-20 alcohols (Fig. 2). We identified these metabolites by comparing their HPLC properties with those of authentic standards and by GC/ MS analysis (35). None of these metabolites were formed in the absence of NADPH, showing that the reaction was P450 mediated. The predominant metabolites, accounting for $70 \%$ of the total products, were EETs and their hydration products, the
CYP1A1

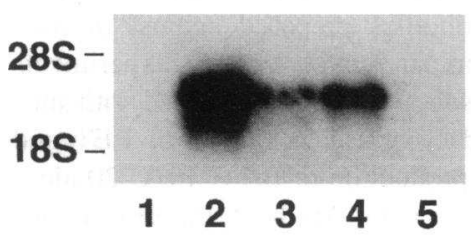

CYP2C

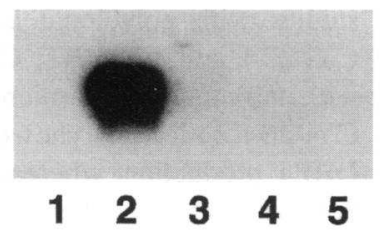

CYP2B4/5

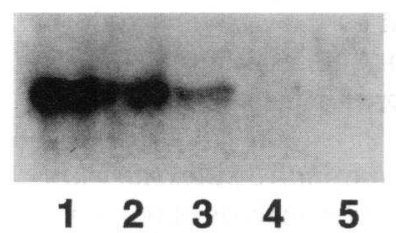

CYP4B1

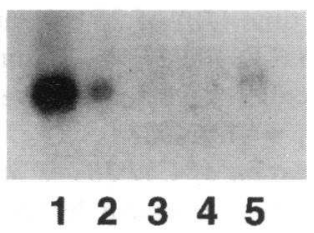

$$
\begin{aligned}
& 1=\text { lung } \quad 3=\text { kidney } \quad 5=\text { brain } \\
& 2 \text { = liver } \quad 4 \text { = heart }
\end{aligned}
$$

Figure 3. Northern blot analysis of poly (A) ${ }^{+}$mRNA extracted from rabbit tissues. $5 \mu \mathrm{g}$ of poly $(\mathrm{A})^{+}$mRNA isolated from rabbit liver, lung, kidney, heart, and brain was submitted to electrophoresis and blot hybridized with 5 ' end sequence-specific oligonucleotide probes to CYP1A1, CYP2B4/5, and CYP4B1, or with a consensus oligonucleotide probe to CYP2C1, CYP2C2, CYP2C3, CYP2C4, CYP2C5, CYP2C14, CYP2C15, and CYP2C16 as described in Methods. 

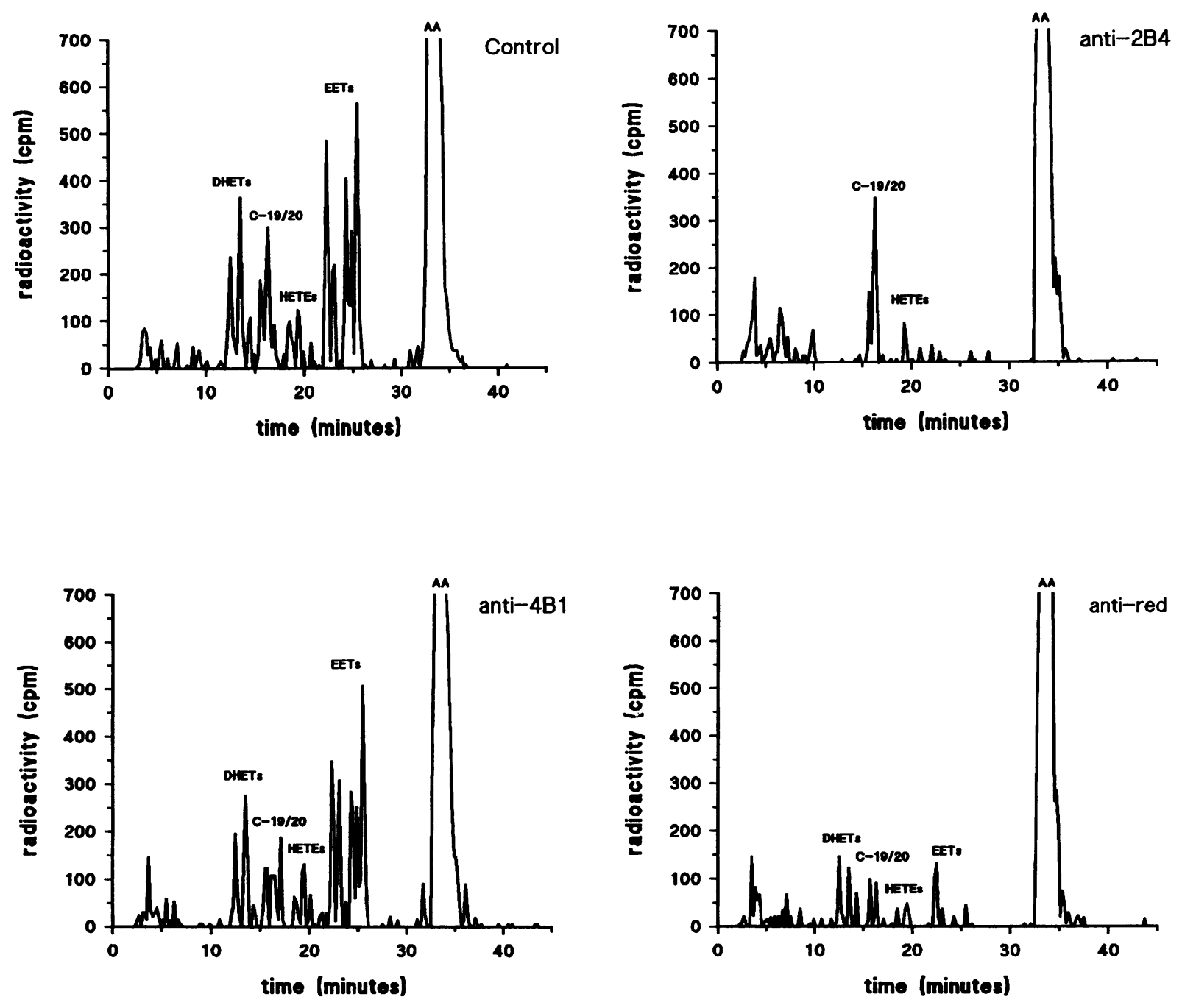

Figure 4. Antibody inhibition studies. Polyclonal IgG antibodies against purified rabbit lung CYP2B4, CYP4B1, and NADPH-cytochrome P450 reductase, or the corresponding control, nonimmune IgG fractions (2-3 mg of IgG per $\mathrm{mg}$ of microsomal protein), were added to the microsomal incubates as described in Methods. $\left[1-{ }^{14} \mathrm{C}\right]$ arachidonic acid was added, and the reaction was initiated with addition of NADPH. The ethyl ethersoluble metabolites were separated by reverse-phase HPLC as described.

DHETs (Fig. 2). The C-19/C-20 alcohols and HETEs accounted for $16 \%$ and $14 \%$ of the total products, respectively (Fig. 2). Regiochemical analysis revealed that the predominant EET regioisomer was 5,6-EET, as shown by the fraction with a retention time $\left(R_{\mathrm{t}}\right)$ of $26 \mathrm{~min}$ and by the recovery of the $\delta$ lactone of 5,6-DHET $\left(R_{\mathrm{t}}=22 \mathrm{~min}\right)$. Similar analysis of the C$19 / C-20$ alcohols revealed that the predominant isomer was 20 $\mathrm{OH}-\mathrm{AA}\left(R_{\mathrm{t}}=16 \mathrm{~min}\right)$.

Identification of CYP2B4 as a constitutive pulmonary arachidonic acid epoxygenase. Northern blot analysis of poly (A) ${ }^{+}$ mRNA extracted from rabbit lung, liver, kidney, heart, and brain was performed using radiolabeled, sequence-specific oligonucleotide probes to CYP1A1, CYP2B4/5, CYP4B1 and a consensus oligonucleotide probe to several $2 \mathrm{C}$ subfamily members (including CYP2C1, CYP2C2, CYP2C3, CYP2C4, CYP2C5, CYP2C14, CYP2C15, and CYP2C16). Message for CYP1A1 was abundant in liver, less abundant in heart and kidney, and present at very low levels in lung (Fig. 3). Message for the $2 \mathrm{C}$ subfamily P450s was also most abundant in liver and undetectable in lung (Fig. 3). In contrast, messages for
CYP2B4/5 and CYP4B1 were present at high levels in lung but were less abundant in extrapulmonary tissues (Fig. 3).

To determine which pulmonary $\mathrm{P} 450$ isoform was responsible for arachidonic acid epoxidation, we performed inhibition studies with polyclonal antibodies prepared against purified CYP2B4 and CYP4B1. Compared with control experiments with nonimmune IgG, microsomal fractions incubated with antiCYP2B4 antibodies showed complete inhibition of EET and DHET production, whereas production of the C-19/C-20 alcohols was largely unchanged (Fig. 4). Antibody titration studies demonstrated that complete inhibition of epoxygenase activity occurred at antibody concentrations as low as $1 \mathrm{mg}$ of $\mathrm{IgG}$ per $\mathrm{mg}$ of microsomal protein. In contrast, anti-CYP4B1 antibodies did not significantly alter P450-mediated metabolism of arachidonic acid at concentrations as high as $3 \mathrm{mg}$ of $\mathrm{IgG}$ per $\mathrm{mg}$ of microsomal protein (Fig. 4). Experiments using antibodies to the NADPH-cytochrome $P 450$ reductase showed a marked (8590\%) inhibition of arachidonic acid metabolism (Fig. 4), thus confirming the role of cytochrome $\mathrm{P} 450$ in arachidonic acid epoxidation and C-19/C-20 oxidation. As shown in Fig. 4, 

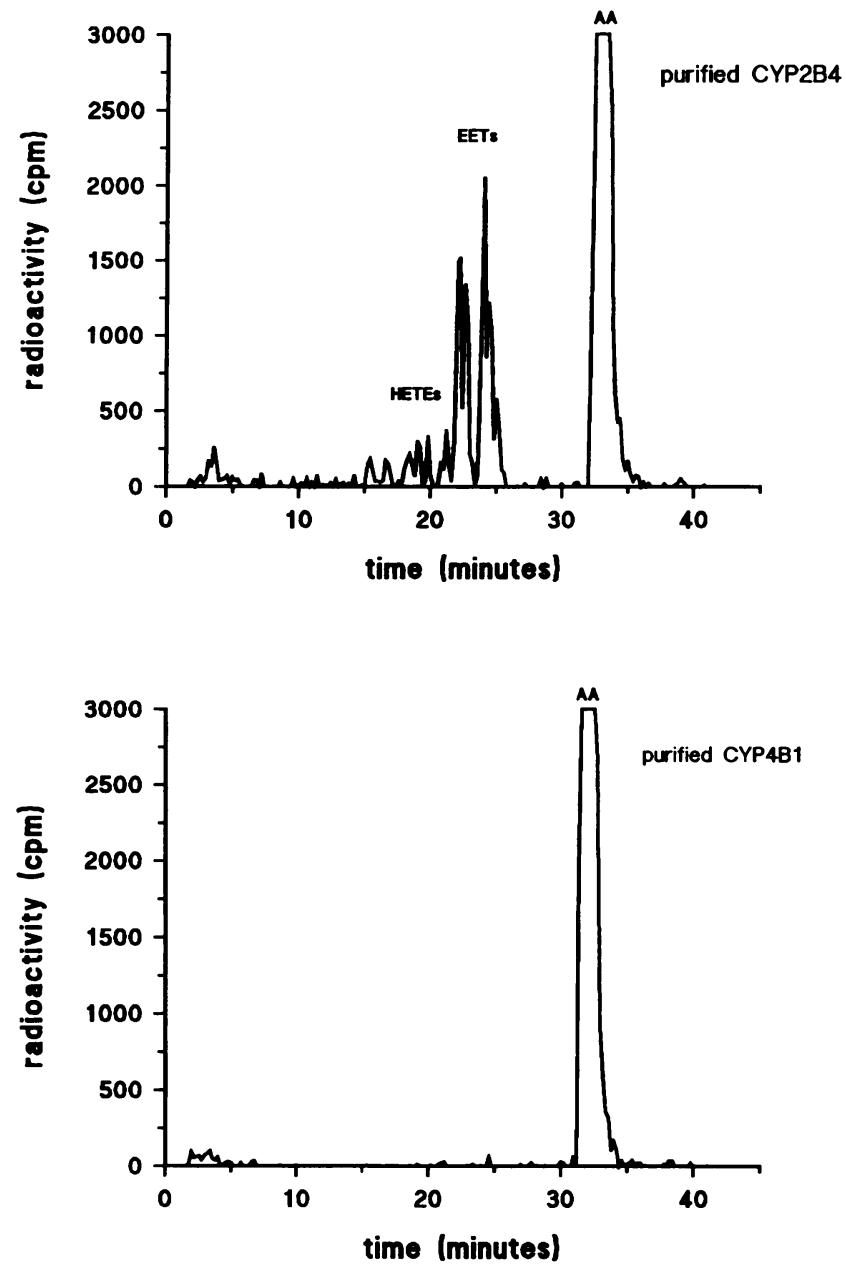

Figure 5. Reverse-phase HPLC chromatogram of organic soluble metabolites generated during incubations of purified CYP2B4 and CYP4B1 with $\left[1-{ }^{14} \mathrm{C}\right]$ arachidonic acid. Purified CYP2B4 or CYP4B1, NADPHcytochrome $\mathrm{P} 450$ reductase, and cytochrome $b_{5}$ were incubated with $\left[1-{ }^{14} \mathrm{C}\right]$ arachidonic acid, NADPH, and an NADPH-regenerating system as described in Methods. Reaction products were resolved by reversephase HPLC as described.

HETE production was minimally altered in the presence of antireductase antibodies, suggesting that HETE formation may be P450 independent.

To evaluate further the $\mathrm{P} 450$ arachidonic acid monooxygenase activity of CYP2B4 and CYP4B1, electrophoretically homogeneous lung P450s (CYP2B4 or CYP4B1), cytochrome $\mathrm{b}_{5}$, and NADPH-cytochrome $\mathrm{P} 450$ reductase were reconstituted in the presence of L- $\alpha$-dilauroyl-sn-glycero-3-phosphocholine and incubated with arachidonic acid in the presence of NADPH. CYP2B4 metabolized arachidonic acid at a rate of $53 \mathrm{pmol}$ of product formed per nmol of $\mathrm{P} 450$ per min, producing primarily EETs (80\% of total) (Fig. 5). Regiochemical analysis of the EET products demonstrated a unique preference for the 5,6EET, as shown by the recovery of 5,6-EET $\left(R_{\mathrm{t}}=25 \mathrm{~min}\right)$ and the $\delta$-lactone of 5,6-DHET $\left(R_{\mathrm{t}}=22 \mathrm{~min}\right)$ (Fig. 5). The regiochemistry of the epoxygenase products formed by CYP2B4 (Fig. 5) was similar to that formed during incubations of rabbit lung microsomal fractions with arachidonic acid (Fig. 2). In contrast, the metabolism of arachidonic acid by CYP4B 1
Table I. Regio- and Stereochemical Composition of Rabbit Lung EETs

\begin{tabular}{lccccc}
\hline & & & \multicolumn{2}{c}{ Enantioselectivity } \\
\cline { 3 - 5 } Regioisomer & Concentration & Distribution & $R, S$ & $S, R$ \\
\hline & $n g / g$ lung & $\%$ total & $\%$ & $\%$ \\
$14,15-$ EET & 147 & 40 & 68 & 32 \\
$11,12-$ EET & 103 & 28 & 38 & 62 \\
8,9-EET & 116 & 32 & 41 & 59
\end{tabular}

Values are the means of at least four different experiments with SE < $15 \%$ of the mean. Distribution is expressed as a percentage of the total lung EETs (5,6-EET not measured).

was undetectable (Fig. 5). The relative abundance of CYP2B4 message in rabbit lung (Fig. 3), together with the documented epoxygenase activity of this hemeprotein (Figs. 4 and 5), indicates that CYP2B4 is the predominant constitutive pulmonary arachidonic acid epoxygenase.

Detection of EETs and DHETs in rabbit lung homogenate and BAL fluid. Rabbit lung homogenate contained $\sim 350 \mathrm{ng}$ of total EET per $g$ of lung (Table I). The major EET regioisomer present in lung homogenate was 14,15-EET ( $40 \%$ of total), followed by roughly equal amounts of 11,12- and 8,9-EET ( 28 and $32 \%$ of total, respectively) (Table I). The labile 5,6-EET suffered extensive decomposition during the extraction and purification process used and therefore could not be quantified. Chiral analysis of rabbit lung EETs revealed that the $14(R), 15(S)$-, $11(S), 12(R)-$, and $8(S), 9(R)$-EET were the predominant antipods (Table I).

BAL fluid contained $\sim 400 \mathrm{pg}$ of total EET per ml of lavage and $150 \mathrm{pg}$ of total DHET per ml of lavage (Table II). The major EET regioisomer present in BAL fluid was 14,15-EET (47\% of total), followed by roughly equal amounts of $11,12-$ and $8,9-$ EET ( 24 and $29 \%$ of total, respectively) (Table II). As before, the labile 5,6-EET could not be quantified. The major DHET regioisomer present in BAL fluid was 5,6-DHET (41\% of total) (Table II). BAL fluid contained smaller amounts of $14,15-, 11,12-$, and 8,9-DHET $(22,15$, and $22 \%$ of total, respectively) (Table II). The majority (69\%) of the total EETs were present within the cellular compartment of BAL fluid. Further-

Table II. Regioisomeric Composition of Rabbit BAL Fluid EETs and DHETs

\begin{tabular}{lcc}
\hline Regioisomer & Concentration & Distribution \\
\hline & $p g / m l$ lavage & \% total \\
14,15-EET & 182 & 47 \\
$11,12-\mathrm{EET}$ & 90 & 24 \\
8,9-EET & 107 & 29 \\
14,15-DHET & 31 & 22 \\
11,12-DHET & 21 & 15 \\
8,9-DHET & 31 & 22 \\
5,6-DHET & 57 & 41 \\
\hline
\end{tabular}

Values are the means of at least five different experiments with $\mathrm{SE}<$ $15 \%$ of the mean. Distribution is expressed as a percentage of the total lung EETs (5,6-EET not measured) or DHETs. 
more, most $(>80 \%)$ of the EETs in both the cellular and extracellular compartments were esterified to phospholipids. Control experiments were performed to confirm that artifactual EET or DHET formation did not occur during the BAL extraction and purification process. Using $0.5 \mathrm{mg}$ of HPLC-purified arachidonic acid added to BAL fluid, we were able to demonstrate that artifactual EET or DHET formation was negligible under the conditions of analysis described in Methods.

Biological activities of $P 450$ arachidonic acid metabolites. Tissue bath studies were performed on 24 cylindrical segments of hilar bronchi from 17 guinea pigs. From an $F_{R}$ of $111.0 \pm 11.6$ $\mathrm{mg}$ (mean $\pm \mathrm{SE}$ ), $F_{\mathrm{MAX}}$ to $1 \mathrm{mM}$ bethanechol was $782.1 \pm 81.8$ mg. $F_{\text {HIST }}$ was $51.1 \pm 2.3 \%$ of $F_{\mathrm{MAX}}$, requiring a concentration of $2.4 \pm 0.3 \mu \mathrm{M}$ histamine. $1 \mu \mathrm{M}$ isoproterenol consistently relaxed the tissues from $F_{\text {HIST }}\left(\Delta F_{\text {HIST }}=-83.0 \pm 2.9 \%\right)$. Both 5,6-EET-Me $(n=3)$ and 8,9-EET $(n=3)$ caused significant concentration-related relaxation of the tissues below $F_{\text {HIST }}$ at concentrations of $10^{-5}-10^{-6} \mathrm{M}\left(\Delta F_{\mathrm{HIST}}=-37.4 \pm 13.0 \%\right.$ and $-24.9 \pm 4.9 \%$ at $10^{-5} \mathrm{M}$ for 5,6-EET-Me and 8,9-EET, respectively, $P<0.05$ ) (Fig. 6, $A$ and $B$ ). Compared with the eicosanoid smooth muscle relaxant $\mathrm{PGE}_{2}(n=3), 5,6-\mathrm{EET}-\mathrm{Me}$ and 8,9-EET were $\sim 6-6.5$-fold less potent at $10^{-6} \mathrm{M}$ and 1.5-2fold less potent at $10^{-5} \mathrm{M}$ in this system (data not shown). $11,12-\mathrm{EET}(n=3)$ caused a mild reduction in contractile force $\left(\Delta F_{\text {HIST }}=-7.3 \pm 3.8 \%\right.$ at $10^{-5} \mathrm{M}, P=0.09$ ), whereas 14,15 EET $(n=3)$ was without effect $\left(\Delta F_{\text {HIST }}=7.7 \pm 7.1 \%\right.$ at $10^{-5}$ M, $P>0.10)$. 20-OH-AA $(n=4)$ caused a marked concentration-related contraction above $F_{\text {HIST }}\left(\Delta F_{\text {HIST }}=+55.0 \pm 23.6 \%\right.$ at $10^{-5} \mathrm{M}, P<0.05$ ) (Fig. $6 C$ ). The ethanol/PSS vehicle ( $n$ $=5$ ) had no significant effect on $F_{\text {HIST }}$ at any tested concentration $\left(\Delta F_{\text {HIST }}=-3.9 \pm 3.2 \%\right.$ at $10^{-3} \mathrm{M}$ ethanol, $\left.P>0.10\right)$. Thus, arachidonic acid is metabolized by the pulmonary cytochrome P450 monooxygenase enzyme system into compounds that both reduce (5,6-EET and 8,9-EET) and increase (20-OHAA) bronchial smooth muscle tone.

\section{Discussion}

Although several studies have suggested a possible link between P450 and hypoxic pulmonary vasoconstriction (31,61), pulmonary P450 has long been thought to function primarily in the metabolism of exogenous compounds, including xenobiotics and inhaled carcinogens (30). Oxygenation of these chemicals has been shown to cause either activation or detoxification (30). Only recently has the pulmonary P450 metabolism of endogenous substances been reported $(33,34)$. We have provided data to suggest an active role of the pulmonary P450 system in the regio- and stereoselective oxygenation of endogenous substrates (arachidonic acid). Incubations of rabbit lung microsomal fractions with radiolabeled arachidonic acid resulted in the formation primarily of EETs (Fig. 2). Regiochemical analysis revealed that the 5,6-EET was the predominant EET regioisomer formed (Fig. 2). The profile of metabolites formed by rabbit lung microsomal fractions was qualitatively different from that reported for rat and rabbit liver microsomal fractions, in which $11,12-$ and 14,15 -EET were the predominant regioisomers (19, 62). The rabbit lung product profile was also different from that observed for rat and rabbit kidney, in which C-19/C-20 alcohols constituted $>50 \%$ of the total products and 11,12EET was the predominant EET regioisomer produced $(5,6$, 20). In fact, rabbit lungs are unique in their selectivity for epoxidation of arachidonic acid at the 5,6 position. This is par-
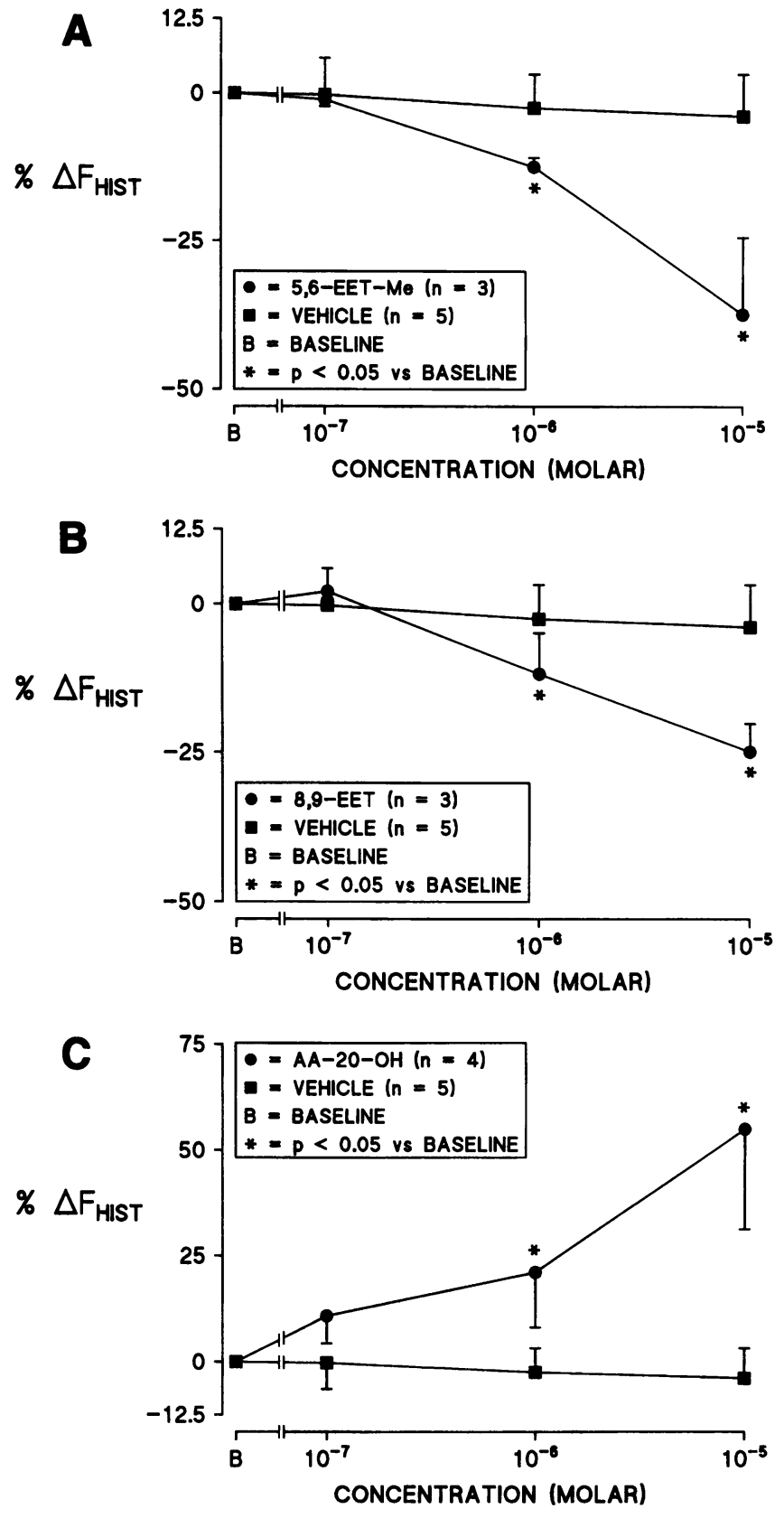

Figure 6. Effects of 5,6-EET-Me, 8.9-ET, and 20-OH-AA on guinea pig bronchial smooth muscle tone. Cylindrical segments of guinea pig hilar bronchi were mounted on a myograph as described in Methods. Tissues were precontracted to $50 \%$ maximal force with histamine, and concentration-response curves were determined using synthetic HPLCpurified P450 arachidonic acid metabolites $\left(10^{-7}-10^{-5} \mathrm{M}\right)$. Values shown are the means of at least three different experiments \pm SE.

ticularly interesting given the important and potent biologic activities attributed to 5,6-EET and/or its methyl ester $(11,63)$. Of note, Oliw and Moldeus (64) have previously observed the rabbit lung microsomal metabolism of arachidonic acid into primarily C-19/C-20 alcohols and PGs, with only small amounts of DHETs produced. The inability of these investigators to detect significant pulmonary microsomal epoxygenase activity may be related to differences in experimental conditions. More recently, Knickle and Bend (65) have demonstrated 
that microsomal fractions prepared from guinea pig lungs metabolize arachidonic acid to C-16 through C-20 alcohols and EETs.

Northern blot analysis revealed that messages for CYP2B4/ 5 and CYP4B1 were present at high levels in rabbit lung but were less abundant in extrapulmonary tissues (Fig. 3). Previous work has shown that message for CYP2B4 is abundant in both rabbit liver and lung (56). Protein immunoblotting studies have shown that, together, the CYP2B4 and CYP4B1 proteins account for better than two-thirds of total rabbit lung microsomal P450 content (30). Additionally, rabbit lung CYP2B4 protein has been immunoquantitated (27). To determine which of the abundant pulmonary P450 isoforms is responsible for arachidonic acid epoxidation in rabbit lung, we performed antibody inhibition studies and purified enzyme reconstitution experiments. Anti-CYP2B4 antibodies completely inhibited EET and DHET production without affecting the production of C-19/C20 alcohols (Fig. 4). Furthermore, electrophoretically homogeneous lung CYP2B4 actively metabolized arachidonic acid, producing primarily EETs (Fig. 5). Importantly, the regiochemistry of the epoxygenase products formed by purified CYP2B4 was strikingly similar to that of the products formed during incubations of rabbit lung microsomal fractions with arachidonic acid (Figs. 2 and 5). The relative abundance of CYP2B4 message and protein in rabbit lung (Fig. 3) $(30,56)$, together with the documented epoxygenase activity of this hemeprotein (Figs. 4 and 5), indicates that CYP2B4 is the predominant constitutive pulmonary arachidonic acid epoxygenase. Previous work has demonstrated that the predominant arachidonic acid epoxygenases present in rat kidney (20), rabbit kidney (66), and guinea pig lung (65) microsomal fractions belong to the CYP2B or CYP2C subfamilies. Additionally, rat liver P450s belonging to the CYP1A and CYP2B subfamilies have been shown to generate EETs (19). Although our data strongly suggest that the predominant constitutive epoxygenase present in rabbit lung is CYP2B4, the additional role of other inducible P450s (e.g., CYP1A1) cannot be excluded based on the data presented.

Whereas in vitro studies are an indispensable tool for the enzymatic characterization of metabolic pathways, they provide only limited information with regard to the in vivo production and concentration of formed metabolites. The documentation of EETs and DHETs as endogenous constituents of rabbit lung provided further evidence to support the in vivo pulmonary P450 metabolism of arachidonic acid. Using a combination of HPLC and GC/MS, we detected substantial amounts of EETs in rabbit lung homogenate (Table I). However, exposure to oxidizing gases can lead to the accumulation of lipid epoxides that originate from nonenzymatic processes (67). A decisive criterion for the enzymatic origin of the lung EETs would be the demonstration of their stereoselective biosynthesis (21). Therefore, we performed chiral analysis of the rabbit lung EETs and demonstrated that the $14(R), 15(S)-, 11(S), 12(R)-$, and $8(S), 9(R)$-EET enantiomers were the predominant antipods (Table I). This stereochemical preference was similar to that previously reported in rat liver (21), kidney (7), and plasma (22). Importantly, since the endogenous enantiomers (i.e., $14(R), 15(S)$-, $11(S), 12(R)$-, and $8(S), 9(R)$-EET) are also the preferred substrates for lung cytosolic epoxide hydrolase (23), the observed EET stereochemical composition (Table I) may underestimate the stereoselectivity of in vivo EET production by the pulmonary epoxygenase $(s)$.
BAL fluid also contained significant quantities of 14,15-, 11,12-, and 8,9-EET (Table II). Unfortunately, the primary metabolite produced during rabbit lung microsomal incubations with arachidonic acid, 5,6-EET (Fig. 2), suffers extensive decomposition during the extraction and purification process and therefore cannot be quantified. However, the concentration of 5,6-DHET, the more stable metabolite of 5,6-EET, can be measured using the techniques described in Methods. Importantly, the major DHET regioisomer present in BAL fluid was 5,6DHET (Table II), thus confirming the in vivo biosynthesis of 5,6-EET and supporting the results obtained from microsomal incubations and purified enzyme reconstitution studies. Perdik et al. (68) have recently reported, in preliminary form, that isolated, perfused rabbit lungs produced arachidonic acid metabolites ex vivo that coeluted with synthetic EETs on reversephase HPLC. They also noted that the production of these metabolites was inhibited by pretreatment with the cytochrome P450 inhibitor, SKF 525-A (68). Their findings are consistent with the demonstration here of EETs in lung homogenate and BAL fluid.

Previous work has shown that, once formed, the EETs may undergo a variety of furtiner metabolic transformations $(2,3)$. First, the EETs can be metabolized by cytosolic or microsomal epoxide hydrolases to produce DHETs $(23,24)$. The cytosolic enzyme not only has high affinity for the EETs $\left(K_{\mathrm{m}}<5 \mu \mathrm{M}\right)$, but also demonstrates a substrate preference for the endogenous enantiomers (23). The detection of DHETs in BAL fluid suggests the in vivo pulmonary hydration of EETs and represents a potential pathway for the metabolism and disposition of these biologically active compounds. Second, the EETs are found esterified to the $s n-2$ position of hepatic glycerophospholipids (44). Stereochemical analysis of hepatic EET-phospholipid pools shows that acylation is stereoselective, with preference for the endogenous enantiomers (44). Our finding that $>80 \%$ of the EETs in BAL fluid were esterified to phospholipids suggests that a similar process occurs in the lung. The presence of membrane phospholipids containing oxidized moieties has been shown to alter cell membrane physicochemical properties, including fluidity $(69,70)$, and may also alter their surface active properties. Thus, one possible role of EET-phospholipids within the airspace may be to modulate the properties of surfactant. Finally, the EETs can be conjugated to glutathione (2) or be further oxidized by either cyclooxygenase $(71,72)$ or by cytochrome P450 monooxygenase (2). Together, these metabolic pathways tightly control the steady-state concentration of the EETs.

The cytochrome P450 arachidonic acid metabolites have been shown to be biologically active both in vivo and in numerous in vitro animal models $(2,3,11,63)$. For example, the EETs $(a)$ stimulate glucagon and insulin release from isolated rat pancreatic islets (14) and somatostatin release from the median eminence $(15) ;(b)$ activate $\mathrm{Na}^{+} / \mathrm{H}^{+}$exchange and are mitogenic in rat renal mesangial cells $(12) ;(c)$ inhibit cyclooxygenase activity and platelet aggregation (16); and $(d)$ cause stereoselective renal artery vasoconstriction (7) and mesenteric (9) and cerebral (73) artery vasodilation. Most of the biologic effects of EETs occur at concentrations of $10^{-7}-10^{-5}$ $M(11,63)$, with the exception of their effects on peptide hormone secretion, which occur in the nanomolar range (15). The effects of the EETs on vascular smooth muscle suggested that cytochrome $\mathrm{P} 450$ arachidonic acid metabolites might also affect lung bronchial smooth muscle tone. We examined the effects 
of synthetic, HPLC-purified P450 arachidonic acid metabolites on airway smooth muscle contractile force using cylindrical segments of guinea pig hilar bronchi. Guinea pigs have been extensively used to study the response of airway smooth muscle to a variety of contractile and relaxant substances, largely because isolated guinea pig airways react in a fashion similar to that of isolated human airways $(74,75)$. Furthermore, the similarities between the guinea pig and the rabbit pulmonary cytochrome $\mathrm{P} 450$ arachidonic acid monooxygenase pathways (65) justify the use of guinea pig bronchi for these studies. We found that both 5,6-EET-Me and 8,9-EET caused significant relaxation of the bronchial tissues, whereas 20-OH-AA caused marked contraction (Fig. 6). Moreover, the EETs affected bronchial smooth muscle tone in vitro at concentrations of $10^{-6}$ $10^{-5} \mathrm{M}$ (Fig. 6), consistent with the known potency of these compounds on mesenteric vascular smooth muscle (9). However, the observed potency of the EETs on bronchial smooth muscle in the present study was less than that of other lipid mediators (e.g., $\mathrm{PGE}_{2}$ ) in this system. The observed biologic actions of the EETs likely depend on their local concentration at the site of activity (i.e., within the microenvironment of the effector cells). Our measurements of EETs in lung homogenate and BAL fluid do not allow for an accurate estimation of local concentrations. Though we cannot rule out that the effects of the EETs on airway smooth muscle are only pharmacologic, the localization of CYP2B4 by immunohistochemistry to cells within the rabbit airway (including Clara and goblet cells) (2628 ), together with the known arachidonic acid epoxygenase activity of this hemeprotein (Figs. 4 and 5), suggests that high levels of the EETs might be attainable in the vicinity of airway smooth muscle.

We studied the biologic effects of 5,6-EET-Me because, in our hands, 5,6-EET is quite labile in aqueous media. Tsubosaka et al. (76) have recently reported in preliminary form that 5,6EET relaxed carbachol-contracted tracheal smooth muscle in vitro in a dose-dependent manner. They further noted that pretreatment with indomethacin, a potent cyclooxygenase inhibitor, reduced the 5,6-EET-dependent tracheal smooth muscle relaxation (76). Whereas 5,6-EET is known to be a substrate for cyclooxygenase, resulting in 5,6-epoxy PGs $(71,72)$, esterified fatty acids (such as 5,6-EET-Me) are poor substrates for this enzyme system (77). Further investigation is required to determine whether 5,6-EET is the biologically active arachidonic acid metabolite, or whether further metabolism by cyclooxygenase is necessary for optimal activity. Cytochrome P450 metabolites of arachidonic acid are known to have effects on $\mathrm{Na}^{+} /$ $\mathrm{K}^{+}$-ATPase $(11,13)$ and calcium ion flux $(78)$, processes that are intimately involved in excitation-contraction coupling. Determining whether the effects of the EETs and/or 20-OHAA on bronchial smooth muscle tone observed in the present study (Fig. 6) are secondary to effects of these metabolites on ion transport or are a consequence of the direct effects of these compounds on the airway smooth muscle will also require further investigation.

In summary, we provide evidence that rabbit lung microsomal fractions metabolize arachidonic acid via cytochrome P450 monooxygenase to form EETs, their hydration products (DHETs), HETEs, and C-19/C-20 alcohols. Antibody inhibition studies and $\mathrm{P} 450$ reconstitution experiments demonstrate that CYP2B4 is a constitutive pulmonary arachidonic acid epoxygenase. We show that both EETs and DHETs are detectable in significant amounts in rabbit lung homogenate and BAL fluid. Chiral analysis of the endogenous EETs confirms their biosynthetic origin. Finally, we show that several of the cytochrome P450 arachidonic acid metabolites alter airway smooth muscle tone in vitro at micromolar concentrations.

In conclusion, our data suggest that, in addition to the cyclooxygenase and lipoxygenase pathways, the cytochrome P450 monooxygenase pathway is an important member of the pulmonary arachidonic acid metabolic cascade. The regio- and stereoselective generation of these unique, biologically active eicosanoids may play an important role in the control of lung homeostasis under normal conditions. Furthermore, altered local concentration of these compounds may contribute to lung dysfunction in selected pathophysiological states.

\section{Acknowledgments}

This work was supported by National Institutes of Health grants GM37922 (J. H. Capdevila), HL27274 (J. R. Snapper), HL07123 (D. C. Zeldin), HL41548 (J. L. Sarek), and GM31278 (J. R. Falck). D. C. Zeldin is the recipient of a fellowship from the Allen and Hanburys Respiratory Institute.

\section{References}

1. Needleman, P., J. Turk, B. A. Jakschik, A. R. Morrison, and J. B. Lefkowith. 1986. Arachidonic acid metabolism. Annu. Rev. Biochem. 55:69-102.

2. Capdevila, J. H., J. R. Falck, and R. W. Estabrook. 1992. Cytochrome P450 and the arachidonic acid cascade. FASEB (Fed. Am. Soc. Exp. Biol.) J. 6:731736, and references therein.

3. Capdevila, J. H., D. Zeldin, K. Makita, A. Karara, and J. R. Falck. 1995. Cytochrome P450 and the metabolism of arachidonic acid and oxygenated eicosanoids. In Cytochrome P450: Structure, Mechanism, and Biochemistry. 2nd Ed. Ortiz de Montellano, editor. Plenum Publishing Corporation, New York. In press.

4. Capdevila, J. H., N. Chacos, J. Werringloer, R. A. Prough, and R. W. Estabrook. 1981. Liver microsomal cytochrome P450 and the oxidative metabolism of arachidonic acid. Proc. Natl. Acad. Sci. USA. 78:5362-5366.

5. Morrison, A. R., and N. Pascoe. 1981. Metabolism of arachidonate through NADPH-dependent oxygenase of renal cortex. Proc. Natl. Acad. Sci. USA. 78:7375-7378.

6. Oliw, E. H., J. A. Larson, A. R. Brash, and J. A. Oates. 1981. Arachidonic acid metabolism in rabbit renal cortex: formation of two novel dihydroxyeicosatrienoic acids. J. Biol. Chem. 256:9924-9931.

7. Katoh, T., K. Takahashi, J. Capdevila, A. Karara, J. R. Falck, H. R. Jacobson, and K. F. Badr. 1991. Glomerular stereospecific synthesis and hemodynamic actions of 8,9-epoxyeicosatrienoic acid in the rat kidney. Am. J. Physiol. 261:F578-F586.

8. Carroll, M. A., M. P. Garcia, J. R. Falck, and J. C. McGiff. 1990. 5,6Epoxyeicosatrienoic acid, a novel arachidonate metabolite: mechanism of vasoactivity in the rat. Circ. Res. 67:1082-1088.

9. Proctor, K., J. Falck, and J. Capdevila. 1987. Intestinal vasodilation by epoxyeicosatrienoic acids: arachidonic acid metabolites produced by a cytochrome P-450 monooxygenase. Circ. Res. 60:50-59.

10. Murphy, R. C., J. R. Falck, S. Lumin, P. Yadagiri, J. A. Zirrolli, M Balazy, J. L. Masferrer, N. G. Abraham, and M. L. Schwartzman. 1988. 12(R)hydroxyeicosatrienoic acid: a vasodilator cytochrome $\mathrm{P450}$-dependent arachidonic acid metabolite from bovine corneal epithelium. J. Biol. Chem. 263:17197-17202.

11. McGiff, J. C. 1991. Cytochrome P450 metabolism of arachidonic acid. Annu. Rev. Pharmacol. Toxicol. 31:339-369.

12. Harris, R. C., T. Homma, H. R. Jacobson, and J. H. Capdevila. 1990. Epoxyeicosatrienoic acids activate $\mathrm{Na}^{+} / \mathrm{H}^{+}$exchange and are mitogenic in cultured rat glomerular mesangial cells. J. Cell. Physiol. 144:429-437.

13. Schwartzman, M., M. Balazy, J. Masferrer, N. Abraham, J. McGiff, and R. C. Murphy. 1987. 12(R)-hydroxyeicosatetraenoic acid: a cytochrome P450 dependent arachidonate metabolite that inhibits $\mathrm{Na}^{+} / \mathrm{K}^{+}$-ATPase in the cornea. Proc. Natl. Acad. Sci. USA. 84:8125-8129.

14. Falck, J. R., S. Manna, J. Moltz, N. Chacos, and J. Capdevila. 1983. Epoxyeicosatrieinoic acids stimulate glucagon and insulin release from isolated rat pancreatic islets. Biochem. Biophys. Res. Commun. 114:743-749.

15. Capdevila, J., N. Chacos, J. R. Falck, S. Manna, A. Negro-Vilar, and S. R. Ojeda. 1983. Novel hypothalamic arachidonate products stimulate somatostatin release from the median eminence. Endocrinology. 113:421-423.

16. Fitzpatrick, F. A., M. D. Ennis, M. E. Baze, M. A. Wynalda, J. E. McGee, and W. F. Liggett. 1986. Inhibition of cyclooxygenase activity and platelet aggre- 
gation by epoxyeicosatrienoic acids: influence of stereochemistry. J. Biol. Chem. 261:15334-15338.

17. Masferrer, J. L., R. C. Murphy, P. J. Pagano, M. W. Dunn, and M. L. Schwartzman. 1989. Ocular effects of a novel cytochrome P450-dependent arachidonic acid metabolite. Invest. Ophthalmol. Vis. Sci. 30:454-460.

18. Masferrer, J. L., J. A. Rimarachin, M. E. Gerritsen, J. R. Falck, P. Yadagiri, M. W. Dunn, and M. L. Schwartzman. 1991. 12(R)-hydroxyeicosatrienoic acid, a potent chemotactic and angiogenic factor produced by the cornea. Exp. Eye Res. 52:417-424.

19. Capdevila, J. H., A. Karara, D. J. Waxman, M. V. Martin, J. R. Falck, and F. P. Guengerich. 1990. Cytochrome P450 enzyme-specific control of the regio- and enantiofacial selectivity of the microsomal arachidonic acid epoxygenase. J. Biol. Chem. 265:10865-10871.

20. Capdevila, J. H., S. Wei, J. Yan, A. Karara, H. R. Jacobson, J. R. Falck, F. P. Guengerich, and R. N. Dubois. 1992. The cytochrome P450 arachidonic acid epoxygenase: regulatory control of the renal epoxygenase by dietary salt loading. J. Biol. Chem. 267:21720-21726.

21. Karara, A., E. Dishman, I. Blair, J. R. Falck, and J. H. Capdevila. 1989. Endogenous epoxyeicosatrienoic acids: cytochrome P450 controlled stereoselectivity of the hepatic arachidonic acid epoxygenase. J. Biol. Chem. 264:1982219827.

22. Karara, A., S. Wei, D. Spady, L. Swift, J. H. Capdevila, and J. R. Falck. 1992. Arachidonic acid epoxygenase: structural characterization and quantification of epoxyeicosatrienoates in plasma. Biochem. Biophys. Res. Commun. 182:13201325.

23. Zeldin, D. C., J. Kobayashi, J. R. Falck, B. S. Winder, B. D. Hammock, J. R. Snapper, and J. H. Capdevila. 1993. Regio- and enantiofacial selectivity of epoxyeicosatrienoic acid hydration by cytosolic epoxide hydrolase. J. Biol. Chem. 268:6402-6407.

24. Chacos, N., J. H. Capdevila, J. R. Falck, S. Manna, C. Martin-Wixtrom, S. Gill, B. D. Hammock, and R. Estabrook. 1983. The reaction of arachidonic acid epoxides (epoxy-eicosatrienoic acids) with a cytosolic epoxide hydrolase. Arch. Biochem. Biophys. 223:639-648.

25. Catella, F., J. A. Lawson, K. J. Fitzgerald, and G. A. Fitzgerald. 1990. Endogenous biosynthesis of arachidonic acid epoxides in humans: increased formation in pregnancy induced hypertension. Proc. Natl. Acad. Sci. USA. 87:58935897.

26. Serabjit-Singh, C. J., S. J. Nishio, R. M. Philpot, and C. P. Plopper. 1988. The distribution of cytochrome $\mathrm{P} 450$ monooxygenase in cells of the rabbit lung: an ultrastructural immuno-cytochemical characterization. Mol. Pharmacol. 33:279289.

27. Domin, B. A., T. R. Devereux, and R. M. Philpot. 1986. The cytochrome P450 monooxygenase system in rabbit lung: enzyme components, activities, and induction in the nonciliated bronchiolar epithelial (Clara) cell, alveolar type II cell, and alveolar macrophage. Mol. Pharmacol. 30:296-303.

28. Dees, J. H., L. D. Coe, Y. Yasukochi, and B. S. Masters. 1980. Immunofluorescence of NADPH-cytochrome c (P450) reductase in rat and minipig tissues injected with phenobarbital. Science (Wash. DC). 208:1473-1475.

29. Waechter, F., P. Bentley, F. Bieri, S. Maukkassah-Kelly, W. Staubli, and M. Villermain. 1988. Organ distribution of epoxide hydrolases in cytosolic and microsomal fraction of normal and nafenopin treated male mice. Biochem. Pharmacol. 37:3897-3903.

30. Philpot, R. M., and B. R. Smith. 1984. Role of cytochrome P450 and related enzymes in the pulmonary metabolism of xenobiotics. Environ. Health Perspectives 55:359-367.

31. Miller, M. A., and C. A. Hales. 1979. Role of cytochrome P450 in alveolar hypoxic pulmonary vasoconstriction in dogs. J. Clin. Invest. 64:666-673.

32. Tindberg, N., and M. Ingelman-Sundberg. 1989. Cytochrome P450 and oxygen toxicity: oxygen dependent induction of ethanol-inducible cytochrome P450 (IIEI) in rat liver and lung. Biochemistry. 28:4499-4504.

33. Okita, R., R. Soberman, J. Bergholte, B. S. Masters, R. Hayes, and R. C. Murphy. 1988. $\omega$-Hydroxylation of 15 -HETE by lung microsomes from pregnant rabbits. Mol. Pharmacol. 32:706-709.

34. Masters, B. S., R. T. Okita, A. S. Muerhoff, M. T. Leithauser, A. Gee, S. Winquist, D. L. Roerig, J. E. Clark, R. C. Murphy, and P. Ortiz de Montellano. 1989. Pulmonary $P 450$ mediated eicosanoid metabolism and regulation in the pregnant rabbit. Adv. Prostaglandins, Leukotrienes Res. 19:335-338.

35. Capdevila, J. H., J. R. Falck, E. Dishman, and A. Karara. 1990. Cytochrome P-450 arachidonate epoxygenase. Methods Enzymol. 187:385-394.

36. Bradford, M. M. 1976. A rapid and sensitive method for the quantification of microgram quantities of protein utilizing the principle of protein-dye binding. Anal. Biochem. 72:248-254.

37. Parandoosh, Z., V. S. Fujita, M. J. Coon, and R. Philpot. 1987. Cytochrome P450 isoenzymes 2 and 5 in rabbit lung and liver: comparisons of structure and inducibility. Drug Metab. Dispos. 15:59-67.

38. Guengerich, F. P., G. A. Dannan, S. T. Wright, M. V. Martin, and L. S. Kaminsky. 1982. Purification and characterization of microsomal cytochrome P450s. Biochemistry. 21:6019-6030.

39. Yasukochi, Y., and B. S. S. Masters. 1976. Some properties of a detergent solubilized NADPH-cytochrome c (cytochrome $\mathrm{P450}$ ) reductase purified by biospecific affinity chromatography. J. Biol. Chem. 251:5337-5344.

40. Serabjit-Singh, C. J., C. R. Wolf, and R. M. Philpot. 1979. The rabbit pulmonary mono-oxygenase system: immunochemical and biochemical characterization of enzyme components. J. Biol. Chem. 254:9901-9907.

41. Vanderslice, R. R., B. A. Domin, G. T. Carver, and R. M. Philpot. 1987. Species-dependent expression and induction of homologues of rabbit cytochrome P450 isozyme 5 in liver and lung. Mol. Pharmacol. 31:320-325.

42. Hammonds, T. D., I. A. Blair, J. R. Falck, and J. H. Capdevila. 1989. Resolution of epoxy-eicosatrienoate enantiomers by chiral phase chromatography. Anal. Biochem. 182:300-303.

43. Capdevila, J. H., E. Dishman, A. Karara, and J. R. Falck. 1991. Cytochrome P450 arachidonic acid epoxygenase: stereochemical characterization of epoxyeicosatrienoic acids. Methods Enzymol. 206:441-453.

44. Karara, A., E. Dishman, J. R. Falck, and J. H. Capdevila. 1991. Endogenous epoxyeicosa-trienoyl-phospholipids: a novel class of cellular glycerolipids containing epoxidized moieties. J. Biol. Chem. 266:7551-7569.

45. Corey, E. J., A. Marfat, J. R. Falck, and J. O. Albright. 1980. Controlled chemical synthesis of enzymatically produced eicosanoids 11-, 12- and 15-HETE from arachidonic acid and conversion to corresponding HPETEs. J. Am. Chem. Soc. 102:1433-1435.

46. Falck, J. R., and S. Manna. 1982. 8,9-Epoxy arachidonic acid: a cytochrome P450 metabolite. Tetrahedron Lett. 23:1755-1756.

47. Moustakis, C. A., J. Viala, J. H. Capdevila, and J. R. Falck. 1986. Enantioselective biosynthesis of epoxyeicosatrienoic acids. J. Am. Chem. Soc. 107:52835285.

48. Mosset, P., D. Yadagiri, S. Lumin, J. H. Capdevila, and J. R. Falck. 1986 Arachidonate epoxygenase: total synthesis of both enantiomers of 8,9- and 11,12epoxyeicosatrienoic acids Tetrahedron Lett. 27:6035-6038.

49. Falck, J. R., P. Yadagiri, and J. H. Capdevila. 1990. Synthesis of epoxyeicosatrienoic acids and heteroatom analogs. Methods Enzymol. 187:357-364.

50. Manna, S., J. R. Falck, N. Chacos, and J. Capdevila. 1983. Synthesis of arachidonic acid metabolites produced by purified kidney cortex microsomal cytochrome P450. Tetrahedron Lett. 24:33-36.

51. Capdevila, J., R. Y. Kim, C. M. Wixtrom, J. R. Falck, S. Manna, and R. W. Estabrook. 1985. Influence of a fibric acid type hypolipidemic agent on the oxidative metabolism of arachidonic acid by liver microsomal cytochrome P450. Arch. Biochem. Biophys. 243:8-19.

52. Capdevila, J. H., B. Pranamik, J. L. Napoli, S. Manna, and J. R. Falck. 1986. Arachidonic acid epoxidation: epoxyeicosatrienoic acids are endogenous constitutents of rat liver. Arch. Biochem. Biophys. 231:511-517.

53. Porter, N. A., J. Logan, and V. Kontoyianidou. 1979. Preparation and purification of arachidonic acid hydroperoxides of biological importance. J. Org. Chem. 44:3177-3181.

54. Maniatis, T., J. Sambrook, and E. F. Fritsch. 1989. Molecular Cloning: A Laboratory Manual, 2nd edition. Cold Spring Harbor Laboratory, Cold Spring Harbor, NY. 7.19-7.48.

55. Okino, S. T., L. C. Quattrochi, H. J. Barnes, S. Osanto, K. J. Griffin, E. J. Johnson, and R. H. Tukey. 1985. Cloning and characterization of cDNAs encoding 2,3,7,8-tetra-chlorodibenzo-p-dioxin-inducible rabbit mRNAs for cytochrome P450 isozymes 4 and 6. Proc. Natl. Acad. Sci. USA. 82:5310-5314.

56. Gasser, R., M. Negishi, and R. M. Philpot. 1988. Primary structure of multiple forms of cytochrome $\mathrm{P} 450$ isozyme 2 derived from rabbit pulmonary and hepatic cDNAs. Mol. Pharmacol. 32:22-30.

57. Gasser, R., and R. M. Philpot. 1989. Primary structures of cytochrome $\mathrm{P} 450$ isoenzyme 5 from rabbit and rat and regulation of species-dependent expression and induction in lung and liver: identification of cytochrome P450 gene subfamily IVB. Mol. Pharmacol. 35:617-625.

58. Hassett, C., and C. J. Omiecinski. 1990. Sequence and gene expression of rabbit cytochrome P450 IIC16: comparison to highly related family members. Nuclei Acids Res. 18:1429-1434.

59. Maniatis, T., J. Sambrook, and E. F. Fritsch. 1989. Molecular Cloning: A Laboratory Manual, 2nd edition. Cold Spring Harbor Laboratory, Cold Spring Harbor, NY. 10.6-10.61.

60. Szarek, J. L., and N. L. Schmidt. 1990. Hydrogen peroxide-induced potentiation of contractile responses in isolated rat airways. Am. J. Physiol. 258:L232L237.

61. Sylvester, J. T., and C. McGowan. 1978. The effects of agents that bind to cytochrome P450 on hypoxic pulmonary vasoconstriction. Circ. Res. 43:429437.

62. Oliw, E. H., F. P. Guengerich, and J. A. Oates. 1982. Oxygenation of arachidonic acid by hepatic monooxygenases: isolation and metabolism of four epoxide intermediates. J. Biol. Chem. 257:3771-3781.

63. Fitzpatrick, F. A., and R. C. Murphy. 1989. Cytochrome P450 metabolism of arachidonic acid: formation and biological actions of "epoxygenase"-derived eicosanoids. Pharmacol. Rev. 40:229-241.

64. Oliw, E. H., and P. Moldeus. 1982. Metabolism of arachidonic acid by isolated rat hepatocytes, renal cells and by some rabbit tissues. Biochim. Biophys. Acta. 721:135-143.

65. Knickle, L. C., and J. R. Bend. 1994. Bioactivation of arachidonic acid 
by the cytochrome P450 monooxygenase of guinea pig lung: the orthologue of cytochrome P450 2B4 is solely responsible for formation of epoxyeicosatrienoic acids. Mol. Pharmacol. 45:1273-1280.

66. Laethem, R. M., C. L. Laethem, and D. R. Koop. 1992. Purification and properties of a cytochrome $\mathrm{P} 450$ arachidonic acid epoxygenase from rabbit renal cortex. J. Biol. Chem. 267:5552-5559.

67. Sevanian, A., J. F. Mead, and R. A. Stein. 1979. Epoxides as products of lipid autooxidation in rat lungs. Lipids. 14:634-643.

68. Perdik, P., K. A. Pritchard, J. Z. Tan, and G. H. Gurtner. 1993. Arachidonic acid is metabolized by cytochrome P450 in the rabbit lung. Am. Rev. Respir. Dis. 147:A920. (Abstr.)

69. Sevanian, A., and P. Hochstein. 1985. Mechanisms and consequences of lipid peroxidation in biological systems. Annu. Rev. Nutr. 5:365-390.

70. Gast, K., D. Sirwer, M. Ladhoff, J. Schreiber, R. Koelsch, and K. Kretschmer. 1982. Auto-oxidation-induced fusion of lipid vesicles. Biochim. Biophys. Acta. 686:99-109.

71. Oliw, E. 1984. Biosynthesis of 5,6-dihydroxy prostaglandin $E_{1}$ and $F_{1 \alpha}$ from 5,6-dihydroxy-eicosatrienoic acid by ram seminal vesicles. Biochim. Biophys. Acta. 686:99-109.

72. Oliw, E. 1984. Isolation and chemical conversion of two novel prostaglandin endoperoxides: 5,6-epoxy-PGG ${ }_{1}$ and 5,6-epoxy $\mathrm{PGH}_{1}$. FEBS (Fed. Eur. Biochem. Soc.) Lett. 172:279-293.
73. Gebremedhin, D., Y. H. Ma, J. R. Falck, R. J. Roman, M. VanRollins, and D. R. Harder. 1992. Mechanism of action of cerebral epoxyeicosatrienoic acids on cerebral arterial smooth muscle. Am. J. Physiol. 263:H519-H525.

74. O'Donnell, S. R., J. C. Wanstall, C. S. Kay, and X. P. Zeng. 1991. Tissue selectivity and spasmogen selectivity of relaxant drugs in airway and pulmonary vascular smooth muscle contracted with $\mathrm{PGF}_{2 \alpha}$ or endothelin. Br. J. Pharmacol. 102:311-316.

75. Muccitelli, R. M., S. S. Tucker, D. W. P. Hay, T. J. Torphy, and M. A Wasserman. 1987. Is guinea pig trachea a good in vitro model of human large and central airways? Comparison of leukotriene-, methacholine-, histamine-, and antigen-induced contractions. J. Pharmacol. Exp. Ther. 243:467-473.

76. Tsubosaka, S., F. Sasaki, T. Ishizaki, Y. Saitoh, T. Nakai, and S. Miyabo. 1993. In vitro effects of 5,6-epoxyeicosatrienoic acid (5,6-EET) on tracheal smooth muscle tone in guinea pigs. Am. Rev. Respir. Dis. 147:A661. (Abstr.)

77. Chacos, N., J. R. Falck, C. Wixtrom, and J. H. Capdevila. 1982. Novel epoxides formed during the liver cytochrome $\mathbf{P} 450$ oxidation of arachidonic acid. Biochem. Biophys. Res. Commun. 104:916-922.

78. Malcolm, K. C., and F. A. Fitzpatrick. 1992. Epoxyeicosatrienoic acids inhibit $\mathrm{Ca}^{+2}$ entry into platelets stimulated by thapsigargin and thrombin. J. Biol Chem. 267:19854-19858. 